\title{
The Relationship Between Serum 25 hydroxy Vitamin D Deficiency and Dietary Pattern in Baxshin Hospital, Sulaimani City
}

\author{
Mohammed I M Gubari \\ Clinical Nutrition Department \\ School of Nutrition and Dietetic \\ Tehran University of Medical Science \\ Tehran, Iran \\ Mohammed.jubari@gmail.com \\ Khalid Anwar Hama-ghareeb \\ Research department \\ General Directorate of Health/Sulaimani \\ Ministry of Health \\ Sulaimani, Iraq \\ Khalidanwar82@gmail.com
}

\author{
Jeza Muhamad Abdul Aziz \\ Baxshin Research Center \\ Baxshin Hospital \\ Ministry of Health \\ Sulaimani, Iraq \\ jezamuhamad@gmail.com
}

Bakhtyar Kamal Muhamed

Department of Anesthesia

College of Technical Health

Sulaimani Polytechnic University

Sulaimani, Iraq

Bakhtyar.talabany@spu.edu.iq

\author{
Fadhil Ahmed Mohialdeen \\ Community Health Department \\ Health Technical College. \\ Sulaimani Polytechnic University. \\ Sulaimani, Iraq \\ fadhilahmed@hotmail.com
}

\author{
Hemn Abdalla Omer \\ Baxshin laboratory \\ Baxshin Hospital \\ Ministry of Health \\ Sulaimani, Iraq \\ hemin852005@gmail.com
}

\begin{abstract}
Vitamin D is one of the fat-soluble vitamins that have a great role in phosphate and calcium balance and bone structure. To our knowledge, there are limited data on the relation between dietary pattern and serum vitamin d concentration. Therefore, the aim of the current study is find out whether, there are any associations between serum vitamin $D$ and with any specific dietary pattern. A cross sectional study was implemented in Baxshen hospital in order to find the prevalence of vitamin $D$ deficiency and its relation with dietary pattern among healthy participants. 1131 participants were enrolled in the current study male and female with age 18 - 65 years old, living in Sulaimani city and its districts have not used any supplement in the past 6 months before enrolling the study. Two questionnaires were used for collecting of data, the first one was included demographical data of the participants. Including their age, gender, marital status, educational level, address, and etc. The second one was data on dietary pattern; particularly we focused on some vitamin $D$ dietary sources. A threeday dietary records estimate was taken from the patients and this data were coded and put in dietary software (windiet) and then analyzed. The age of the sample ranged from 18 to 65 years old with the mean of 34.34 years old with a standard deviation of 12.6. One hundred sixty-two (14.3\%) of the 1131 participants were female, nine hundred sixty-nine (85.7\%) of the participants were male. $65.5 \%$ of them exposure to sun less than 30, $34.5 \%$ exposure to sun more than half hour. About $84.6 \%$ of participants had severe deficiency of vitamin $D$ and $6.9 \%$ of participants had adequate vitamin $D$. Fish, eggs and yogurt conception was common among those participants whom their serum vitamin $D$ was adequate, in contrary, there were less consumed among those who had vitamin $D$ deficiency. The percentage of obese $\mathbf{( 9 9 . 8 \% )}$ was significantly higher than normal weight
\end{abstract}

and overweight among severe deficiency Vitamin $D$. Furthermore, a highly percentage of adequate was (93.6\%) in the normal weight. The mean of vitamin $D$ intake was $761 \pm 195.65 \mathrm{IU}$, in normal weight group, and the mean of vitamin $d$ intake was $125.98 \pm 53.15$ $I U$, in obese group. This study has concluded that the reach Dietary sources of vitamin $D$ is not enough to provide the body adequate amount of vitamin $D$, in addition, Obese and overweight individuals tend to have less serum vitamin $D$ status compared to normal weight individuals and finally recommended daily amount of vitamin $d$ intake should be established for Kurdistan people.

Keywords: 25-hydroxy vitamin D, Dietary intake, Dietary pattern, Vitamin D deficiency

\section{INTRODUCTION}

Vitamin D deficiency has been shown to occur globally [1]. With all the medical advances of the century, vitamin D deficiency is as yet plagued. Over a billion people worldwide are vitamin $\mathrm{D}$ deficient or insufficient [2]. In Middle East countries, high variation in serum $25(\mathrm{OH}) \mathrm{D}$ levels was revealed. The lowest level of $3.6 \mathrm{ng} / \mathrm{ml}(9 \mathrm{nmol} / \mathrm{L})$ was seen in a study conducted on older persons in Saudi Arabia [2]. Vitamin D is a prohormone that has a key role in calcium and phosphate balance and bone structure [3, 4]. Normal bone growth and mineralization depend on the availability of adequate calcium and phosphate. Deficient mineralization can result in rickets and/or osteomalacia. In addition, Vitamin D deficiency is related to osteomalacia and rickets in children[5] and with osteoporosis among elderly in institutions[6]. The best biomarker quantified to assess vitamin D status is the serum concentration of 25-hydroxyvitamin D (S- 
25(OH)D) [7, 8]. Vitamin D, also described as "the Sun Vitamin" is a steroid with hormone-like activity. While daylight exposure is that the major source of circulating serum $25(\mathrm{OH}) \mathrm{D}$. It regulates the functions of over two hundred genes and is crucial for growth and development. There are two kind of vitamin D. Vitamin D2 (Ergocalciferol) and vitamin D3 (Cholecalciferol) [9]. Vitamin D status depends on the assembly of vitamin D3 within the skin below the influence of ultraviolet light from sun and D intake through diet or vitamin D supplements. Usually, 50 to $90 \%$ of vitamin $\mathrm{D}$ is created by sunshine exposure of skin and also the remainder comes from the diet [1]

People advised on the danger of sun exposure, and are exposed to the increased use of sunscreen lotion and time spends indoor which has likely contributed to less vitamin $\mathrm{D}$. The contribution of dietary sources to vitamin d status is not clearly known. Some studies have shown that dietary intake of certain vitamin $\mathrm{D}$ reach foods had a significant positive influence on serum 25$\mathrm{OH}$ D concentrations. Natural diet, most humans consume, contain little vitamin D. Traditionally the human vitamin D system begins within the skin, not in the mouth. However, the important sources of vitamin D are egg yolk, fatty fish, Red meat fortified dairy products and beef liver [10].

Vitamin D3 deficiency can result in obesity, diabetes, high blood pressure, depression, fibromyalgia, chronic fatigue syndrome, osteoporosis and neuro-degenerative diseases including Alzheimer's disease. Vitamin D deficiency has been associated with an increased risk of several medical conditions like cancers, especially breast, prostate, and colon cancers. Current research indicates that vitamin $\mathrm{D}$ deficiency plays a role within causing seventeen varieties of different cancers as well as heart disease, stroke, autoimmune diseases, birth defects, and periodontal disease [11].

To our knowledge, there are limited data on the relation between dietary pattern and serum vitamin D concentration. Therefore, the aim of the current study is to find out whether there are any associations between serum vitamin D and with any specific dietary pattern.

\section{METHODS AND MATERIALS}

A cross-sectional study was implemented in Baxshin hospital in order to find the prevalence of vitamin D deficiency and its relation to the dietary pattern among healthy participants. An announcement was distributed through Baxshin hospital main page and Baxshin hospital social media. 2500 participant were agreed to participate in this study. 1131 participants were enrolled, and the rest were excluded because they were not met our inclusion criteria. The target groups were healthy male and female with age 18-65 years old, living in Sulaimani city and its districts, have not used any supplement in the past 6 months before enrolling in the study.

Data collection: Data were collected during 6 months from 21-12-2017 till 21-6-2018. Two questionnaires were used for collecting of data, the first one was included demographical data of the participants which including age, gender, marital status, educational level, address, and etc. The second one was data on the dietary pattern; particularly we focused on some vitamin D dietary sources. A three-day dietary records estimate was taken from the patients and this data were coded and put in dietary software (windiet) and then analyzed.

Blood Samples and Laboratory Analysis: Fasting blood samples were collected from the antecubital vein of all enrolled participant. Samples were sent to the clinical laboratory at Baxshin Hospital in Sulaimani City, for serum $25(\mathrm{OH}) \mathrm{D}$ concentrations assay. The tests were performed using the Roche Cobas e411 immunoassay analyzer using the Roche Elecsys vitamin D3 assay (Roche Diagnostics, Mannheim, Germany). Vitamin D status was categorized as adequate $25(\mathrm{OH}) \mathrm{D}$ $>75 \mathrm{nmol} / \mathrm{L}(>30 \mathrm{ng} / \mathrm{ml})$, insufficient $(25(\mathrm{OH}) \mathrm{D}=50-74$ $\mathrm{nmol} / \mathrm{L}$ or $20-29.6 \mathrm{ng} / \mathrm{ml})$, and deficient $(25(\mathrm{OH}) \mathrm{D}<50$ $\mathrm{nmol} / \mathrm{L}$ or $<20 \mathrm{ng} / \mathrm{ml})$. Serum $25(\mathrm{OH}) \mathrm{D}$ concentration $<$ $25 \mathrm{nmol} / \mathrm{L}(<10 \mathrm{ng} / \mathrm{ml})$ was considered severe vitamin D deficiency [12]

Data analysis: Data for this study were analyzed using statistical software SPSS version 22. Descriptive statistics were applied to find percentage and frequency of the variables as well as a mean standard deviation for continuous variables. Analytical statistics were implemented including Chi-square to find the relation between vitamin $\mathrm{d}$ status and the categorical variables. Significant of the relationship was the test at the p-value less than 0.05 .

\section{RESULTS}

The age of the sample ranged from 18 to 65 years old with the mean of 34.34 years old with a standard deviation of 12.6. One hundred sixty-two (14.3\%) of the 1131 participants were female, nine hundred sixty-nine $(85.7 \%)$ of the participants were male. Eight hundred Fifty-one $(75.2 \%)$ were married, 280 (24.8\%) were single. The majority were Postgraduate $(n=363,32.1 \%)$. In addition, 75 identified themselves had a Bachelor's degree $(6.6 \%)$, and 162 participants were illustrated $(14.3 \%)$. Majority of participants were from outside (76.1\%), only 23.9 were from inside. $65.5 \%$ of the exposure to the sun less than half hour, $34.5 \%$ exposure to the sun more than half hour. These results are presented in Table 1. The (Figure 1) shows that $84.62 \%$ of participants had to severe deficiency of vitamin D and about $7 \%$ of participants had adequate vitamin D. Among those participants who had less than half hour of sun exposure severe vitamin D deficiency was (80.9\%). However, about $7 \%$ had adequate vitamin D Among those participants who had more than 30 minutes of sun exposure (Figure 2). Fish consumption 4 times a month was higher $70.97 \%$ among adequate vitamin D group and for severe deficiency of vitamin D those participants not eaten fish was $90.66 \%$ (Figure 3). Yogurt consumption among participants Illustrated in (Figure 4), for adequate group (100\%) had daily yogurt consumption. And not eaten yogurt was (91.04\%) in severe deficiency group. Regarding egg consumption, daily and four times, a week were (100\%, 100\%) 
consequently in the adequate group. In addition, not eaten $(91.04 \%)$ and two times a week $(95.11 \%)$ were mostly in severe deficiency group (Figure 5). More than two time for meat and chicken consumption was (100\%) in adequate group of vitamin D, so $(91.04 \%)$ in severe deficiency group had not eaten meat, with $(90.4 \%)$ had two time a week as shown in (Figure 6).

Dietary fat intake among all healthy participants, according to the result showed in (Figure 8) among adequate group (100\%) had high fat diet, only $(2.77 \%)$ had taken not the fat diet. In severe deficiency group, the majority of participants had not fat diet intake (88.37\%). Table (2) describes the association between the Vitamin $\mathrm{D}$ status and the body mass index. There is a significant relationship between vitamin D deficiency and BMI $(p<0.001)$. By increasing body weight the severity of vitamin $\mathrm{D}$ deficiency will increase. The percentage of obese $(99.8 \%)$ was significantly higher than normal weight and overweight among severe deficiency Vitamin D. Furthermore, a highly percentage of adequate was (93.6\%) in the normal weight.

According to table (4) the majority of those participants live inside the city $(84.3 \%)$ had severe vitamin D deficiency. Also, among those participants live outside cities the majority $(85.6 \%)$ had severe deficiency of vitamin $\mathrm{D}$. With significant association between address and vitamin D status $(\mathrm{p}=0.003)$. Table (5) shows that there was a highly significant difference between the vitamin D and BMI regarding their Dietary intake. More than 86.73 percent of the participant was obese and $7.17 \%$ were normal weight. The obese higher risk to have vitamin D deficiency compared to normal weight and the mean of vitamin D intake was $761.85 \pm 195.65$ IU, in normal weight group, and the mean of vitamin D intake was $125.98 \pm 53.15 \mathrm{IU}$, in the obese group.

Table 2: The relationship between serum vitamin D status and BMI

\begin{tabular}{|c|c|c|c|c|}
\hline \multirow[b]{2}{*}{ BMI } & \multicolumn{3}{|c|}{ Vitamin D } & \multirow[b]{2}{*}{$P$ value } \\
\hline & $\begin{array}{c}\text { Severe } \\
\text { Deficiency } \\
(\%) \\
\end{array}$ & $\begin{array}{c}\text { Deficiency } \\
(\%)\end{array}$ & $\begin{array}{c}\text { Adequate } \\
(\%)\end{array}$ & \\
\hline $18.5-25$ & $0(0.0)$ & $8(8.3 \%)$ & 73 (93.6) & \multirow{3}{*}{$<0.001$} \\
\hline $25-30$ & $2(0.2)$ & 67 (69.8) & $0(0.0)$ & \\
\hline More than 30 & 955 (99.8) & $21(21.9)$ & $5(6.4)$ & \\
\hline
\end{tabular}

Table 1: Distribution of demographical data of the participants.

\begin{tabular}{|c|c|c|}
\hline Variable & Frequency & $\%$ \\
\hline \multicolumn{3}{|l|}{ Gender } \\
\hline Male & 162 & 14.3 \\
\hline Female & 969 & 85.7 \\
\hline \multicolumn{3}{|l|}{ Education } \\
\hline Illiterate & 162 & 14.3 \\
\hline Primary & 231 & 20.4 \\
\hline Secondary & 123 & 10.9 \\
\hline Preparatory & 177 & 15.6 \\
\hline University & 75 & 6.6 \\
\hline Postgraduate & 363 & 32.1 \\
\hline \multicolumn{3}{|l|}{ Marital state } \\
\hline Marred & 851 & 75.2 \\
\hline Single & 280 & 24.8 \\
\hline \multicolumn{3}{|l|}{ Address } \\
\hline Inside & 861 & 76.1 \\
\hline Outside & 270 & 23.9 \\
\hline \multicolumn{3}{|l|}{ Sun exposure } \\
\hline less than 30 minute. & 741 & 65.5 \\
\hline More than 30 minute & 390 & 34.5 \\
\hline Age $($ mean \pm SD $)$ & $34.34 \pm 2.6$ & \\
\hline
\end{tabular}

Table 3: Daily amount of vitamin D intake.

\begin{tabular}{|l|c|c|c|c|}
\hline $\begin{array}{c}\text { Vitamin D } \\
\text { status }\end{array}$ & Number & Mean & $\begin{array}{c}\text { Std. } \\
\text { Deviation }\end{array}$ & P value \\
\cline { 1 - 4 } $\begin{array}{l}\text { Severe } \\
\text { Deficiency }\end{array}$ & 957 & 121.29 & 15.720 & \multirow{2}{*}{$<0.001$} \\
\cline { 1 - 4 } Deficiency & 96 & 173.88 & 14.309 & \\
\cline { 1 - 4 } Adequate & 78 & 826.15 & 15.239 & \\
\cline { 1 - 4 } Total & 1131 & & & \\
\hline
\end{tabular}

Table 4: Relationship between vitamin D status and address.

\begin{tabular}{|l|c|c|c|}
\hline \multirow{2}{*}{ Vitamin D status } & \multicolumn{2}{|c|}{ Address } & \multirow{2}{*}{ P value } \\
\cline { 2 - 3 } & inside city & Outside city & \\
\hline sever deficiency & $726(84.3)$ & $231(85.6)$ & \multirow{2}{*}{0.003} \\
\hline Deficiency & $84(9.8)$ & $12(4.4)$ & \\
\hline Adequate & $51(5.9)$ & $27(10.0)$ & \\
\hline
\end{tabular}

Table 5: Relationship between BMI and Dietary intake of vitamin $\mathrm{D}$.

\begin{tabular}{|c|c|c|c|c|}
\hline BMI & $\begin{array}{c}\text { Number } \\
(\boldsymbol{\%})\end{array}$ & Mean & Std. Deviation & P value \\
\hline $18.5-25$ & $81(7.17)$ & 761.85 & 195.656 & \\
\cline { 1 - 4 } $25-30$ & $69(6.1)$ & 172.62 & 17.688 & \multirow{2}{*}{$<0.001$} \\
\cline { 1 - 4 } $\begin{array}{c}\text { More than } \\
\text { 30mnt }\end{array}$ & $981(86.73)$ & 125.98 & 53.155 & \\
\hline
\end{tabular}




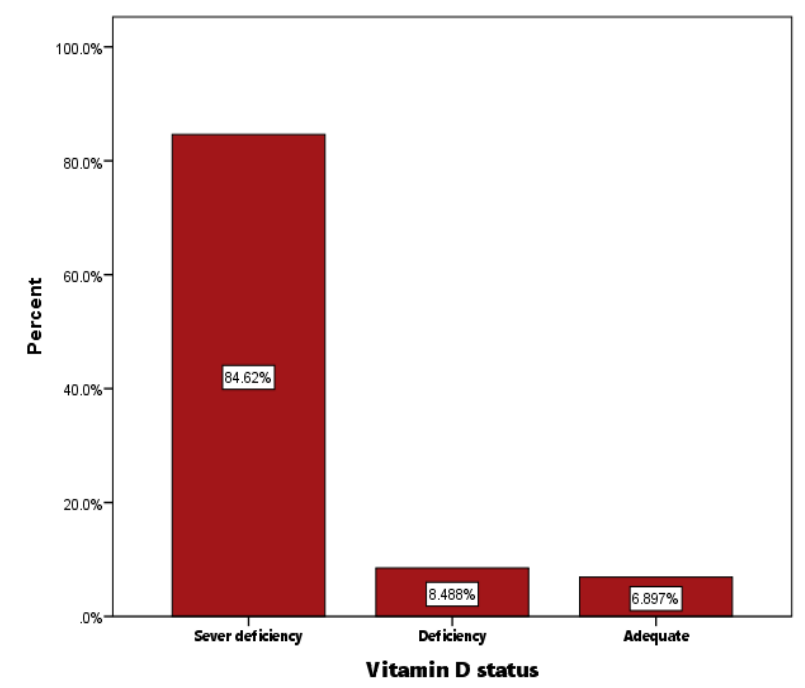

Figure 1: Prevalence of vitamin D deficiency among studied group.

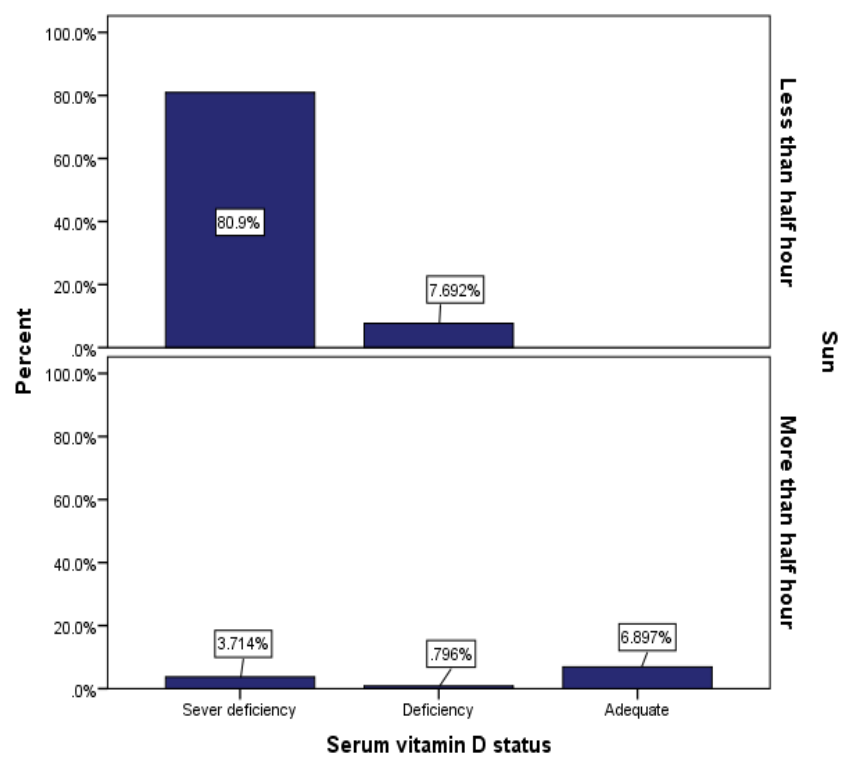

Figure 2: Vitamin D deficiency and its relations to sun exposure.

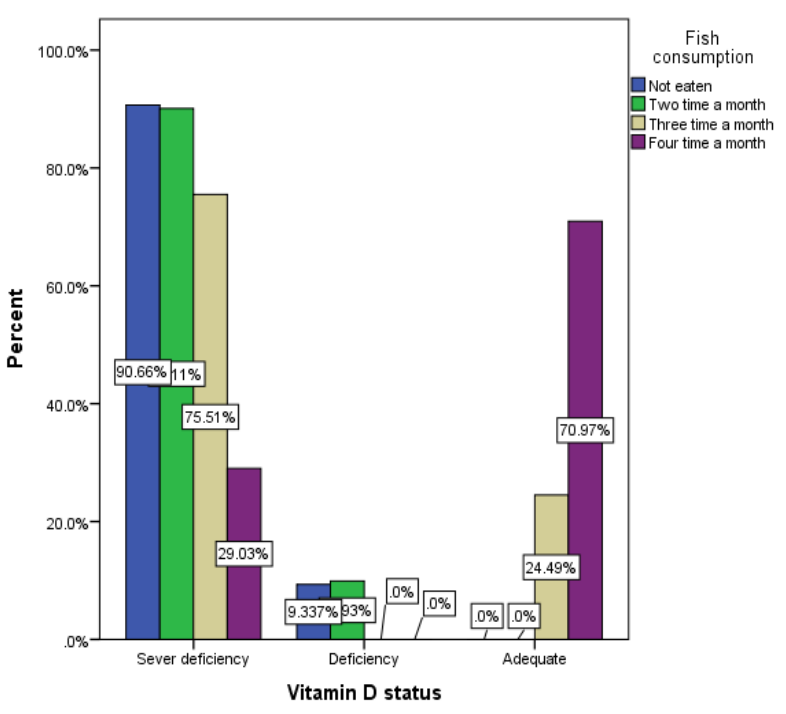

Figure 3: Fish consumption of the studied group

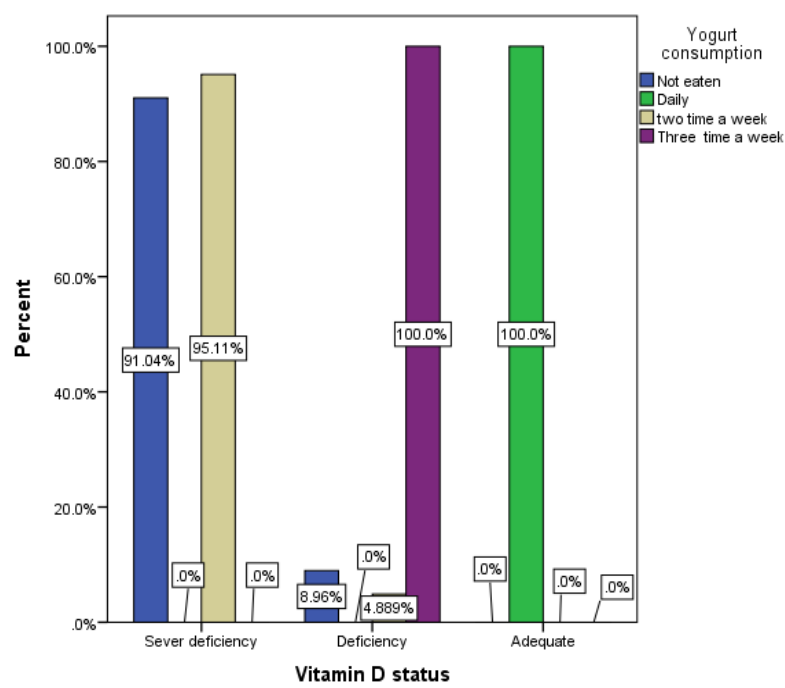

Figure 4: Yogurt consumption of the studied group.

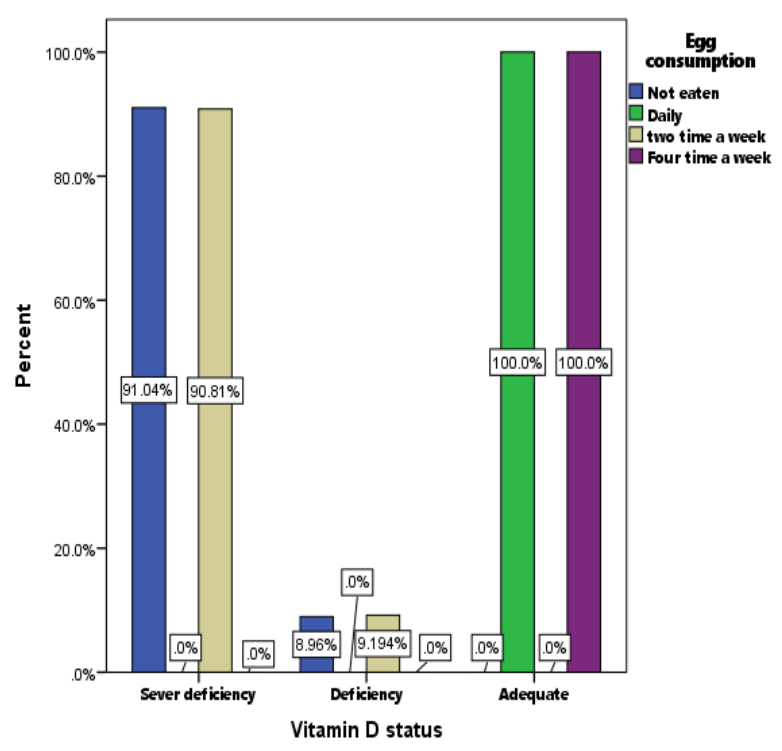

Figure 5: Egg consumption of the studied group.

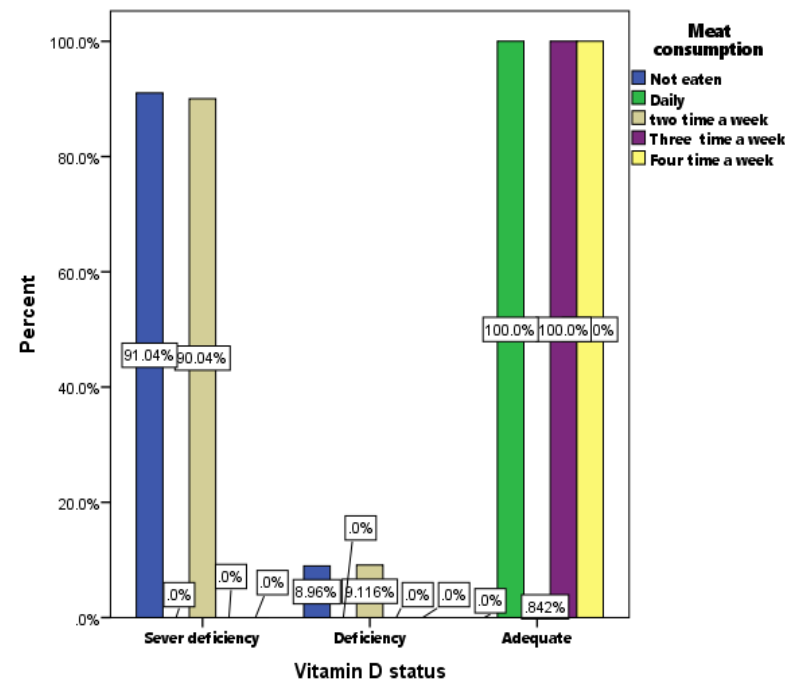

Figure 6: Meat consumption of the studied group 


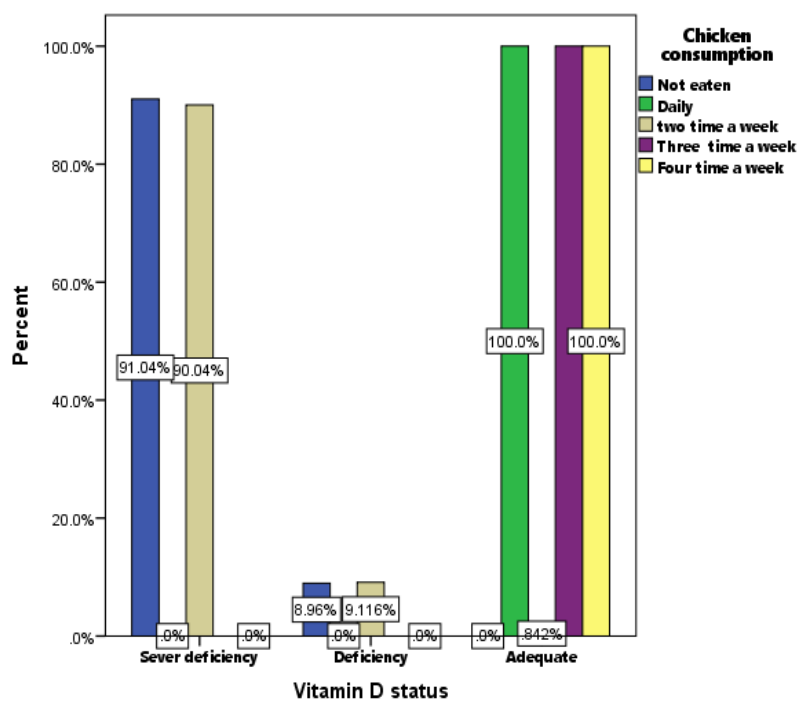

Figure 7: Chicken consumption of the studied group

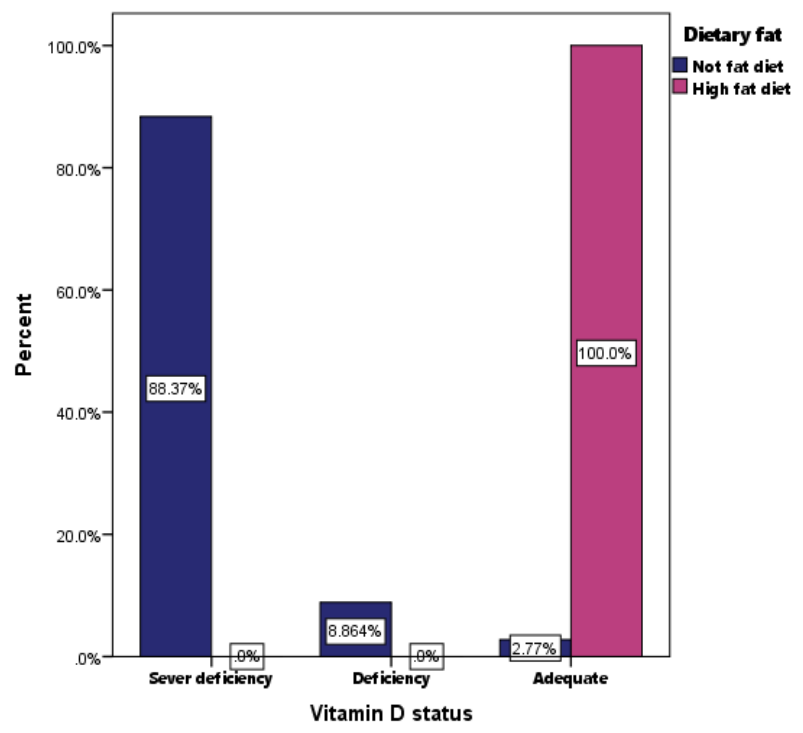

Figure 8: Dietary fat consumption of the studied group

\section{DISCUSSION}

This is the first study aimed to find the prevalence of vitamin D deficiency and its association with the dietary pattern in Kurdistan. Vitamin D status is the best established by measuring serum 25(OH)D concentrations since this value is reflective of both oral intake and subcutaneous vitamin D production. The current recommendation regarding vitamin $\mathrm{D}$ intake [Dietary Reference Intakes (DRI)] within the United State is $400 \mathrm{IU}$ (International Unit)/ day; however, it has been recommended that this recommendation does not result in adequate vitamin $\mathrm{D}$ concentrations within the body. A recent meta-analysis demonstrated a significant positive association comparable to an increase of 1-2 nmol/l in serum 25 OHD level for every 100 additional units of vitamins D. Serum 25-hydroxyvitamin D $[25(\mathrm{OH}) \mathrm{D}]$ concentrations that are between 25-37.5 $\mathrm{nmol} / \mathrm{L}(10-15 \mathrm{ng} / \mathrm{ml})$ are considered to be inadequate and come along with the risk of rickets (deformation of bones because of inadequate development) in children and of osteomalacia (brittle bones) in adults, whereas concentrations that are $\geq 75 \mathrm{nmol} / \mathrm{L}(30 \mathrm{ng} / \mathrm{ml})$ are within the normal range and are optimal for bone health as well as for nonskeletal health benefits of vitamin $\mathrm{D}$, and serum concentrations that are $\geq 500 \mathrm{nmol} / \mathrm{L}(200 \mathrm{ng} / \mathrm{ml})$ are considered to be toxic [13-15].

Vitamin D deficiency in Arab countries had been established in several research studies [16, 17]. This study found that Vitamin D deficiency was not significantly different between female and male ( $P$ $=0.1$ ). But in the other part of Arab world including Qatar and Saudi Arabia, several studies showed Females had 3-fold higher prevalence of Vitamin D deficiency or relative insufficiency than males, their explanation for this finding is related to the traditional dress- style society which cover their body completely due to cultural and religious reasons so that the sun hit the skin is minimal $[16,18,19]$.

Although, Sulaimani province is a sunny climate at summer season and due to high daytime temperature, therefore direct exposure to the sunlight is limited. The research study recorded higher percentage $(80.9 \%)$ of participant have less than 30mint sunlight exposure per day in summer and winter then shown a severe deficiency, so that sunlight exposure was insufficient to induce cutaneous vitamin D3 synthesis during the summer and winter months $[19,20]$. This may be related to inhibition $\mathrm{D}$ activation process every 15 minutes to prevent its accumulation in the blood, therefore, the best exposure period to sunlight was found to be 15 or about 40-45 minutes [21]. Seasons of year and geographical location affect vitamin D Production. people have less sun exposure in winter and the sun is at an angle that limits the amount of ultraviolet burn (UV-B) radiation that hits the earth as a result more UV-B photons are able to penetrate the ozone layer in the spring and summer because the sun is directly overhead. In winter, vitamin producing UV-B photons pass through the ozone layer at an oblique angle and absorbed by the ozone in greater percent [22, 23].

Sensible sun exposure can provide an adequate amount of vitamin D3 that is hold in the body fat and released during the winter, when vitamin D3 cannot be made. Exposure of arms, face and legs for 5 to 30 minutes is often adequate [24]. Duration exposure to sunlight, in the early morning (sunrise to 11:00 a.m.) or late afternoon (3:00 p.m.) is believed to be reasonably safe [25].

Data reported in the present study, the participant in the outside city they had an adequate percentage of vitamin $\mathrm{D}$ than the inside city (10.0 and 5.9) respectively. This is related to the activity population in the inside city which has limited outdoor activity during daytime than outside city activity then sunlight might not even hit their faces. However, air pollution in the inside city which affect the amount of UVB radiation reaching the earth's surface [24]. Similar results among young adults in the innercity of America had shown deficient Vitamin D [26]. Also, the current lifestyle with most activities taking place in the indoors lead to prevents sufficient sun expose. In addition, season and latitude may diminish the intensity of the sun, and also clothing, sunscreen, and skin pigmentation interfere with vitamin D synthesis. In this case, dietary intake becomes 
increasingly important. However, only a few foodstuffs, mainly of animal origin (e.g., fish, meat, offal, egg, dairy product), are the valuable sources of naturally occurring vitamin D-3 [27].

The study result revealed that participants had daily yogurt consumption shows $(100 \%)$ in the adequate group. While, not eaten yogurt was $(91.04 \%)$ in severe deficiency group. vitamin $\mathrm{D}$ content in dairy products yielded the following values: whole milk, $0.3-1.0 \mu \mathrm{g} / \mathrm{kg}$ cream, 3.7-10.8 $\mu \mathrm{g} / \mathrm{kg}$; butter, 5.9-14.1 $\mu \mathrm{g} / \mathrm{kg}$; yogurt, 0.4-6.0 $\mu \mathrm{g} / \mathrm{kg}$; curd cheese, $2.0-7.05 \mu \mathrm{g} / \mathrm{kg}$; soft cheese, $2.8-5.8 \mu \mathrm{g} / \mathrm{kg}$; semi hard and hard cheese, 2.0-18.1 $\mu \mathrm{g} / \mathrm{kg}$. goat's milk, 0.6-2.8 $\mu \mathrm{g} / \mathrm{kg}$; ewe's milk, $1.8 \mu \mathrm{g} / \mathrm{kg}$ [27]. However, the detected values partly vary considerably among the different studies. Typical vitamin D fortified foods include milk, buttermilk, and soft milk products such as yoghurt and in case of dry milky according to the US Code of Federal Regulations the level of vitamin D should be 400 IU per litter [14]. Fortunately, vitamin D fortified dairy product is available in Sulaimani market to include milk, buttermilk, and yogurt.

Regarding egg, this is one of the Kurdish breakfast meal consumption. Study was found daily and four times a week were $(100 \%, 100 \%)$ consequently in the adequate group. In addition, not eaten $(91.04 \%)$ and two times a week $(95.11 \%)$ were mostly in severe deficiency group. Egg contains approximately 20 IU of vitamin D/egg. Also, Fatty fish provides 200-350 IU of vitamin D/100 grams [13]. Low content of vitamin D in the meal may lead to decreasing serum vitamin D levels in Kurdish people.

In the present study found increasing Body Mass Index (BMI)of participant reported the severity of vitamin D deficiency. The (BMI) more than 30 showed higher percent severe Vitamin D deficient (99.8\%) and lower dietary intake, $125.98 \mathrm{IU}$ than the normal weight and overweight $(p<0.001)$. This is consistent with similar studies reported that a strong relationship found between obesity and vitamin D deficiency [18, 28]. Obese individuals reported lower level concentrations of circulating $25(\mathrm{OH})$ vitamin D. Since vitamin D is stored deep in the adipose tissue and not available for secretion into the blood [13]. Mechanism of this association is related to elevated concentrations of 1,25-dihydroxy vitamin D stimulate lipogenesis and inhibit lipolysis in cultured human adipocytes, leading to accumulation of fat [29]. Moreover, 1,25-dihydroxy vitamin D inhibits the expression of adipocyte uncoupling protein 2 (UCP2), which would cause a reduction in the adipocyte's metabolic efficiency [30].

The study found that the participants have a dietary vitamin D intake showed more significant different $(p<0.001)$. (121.29 $\pm 15.720 \mathrm{IU} /$ day $)$ reported in the severe deficiency level while $(821.15 \pm 15.239$ IU/day) found in the adequate. With sufficient UVB exposure, dietary intake of vitamin $\mathrm{D}$ is not necessary but, due to environmental influences synthesis of vitamin $D$ is not always adequate; therefore, dietary intake is advisable. They require amount of vitamin $\mathrm{D}$ for females and males between 9 and 70 years of age in the United States is set at $15 \mu \mathrm{g} / \mathrm{d}(600 \mathrm{IU} / \mathrm{d})$ and also the Endocrine Society suggests this amount for adults aged 19-50 years but indicates that to increase the blood level of $25(\mathrm{OH})-\mathrm{D}-3$ consistently above $30 \mu \mathrm{g} / \mathrm{L}$, at least $37.5-50.0 \mu \mathrm{g} / \mathrm{d}(1500-2000 \mathrm{IU} / \mathrm{d})$ of vitamin D may be required. The German-speaking nutrition societies (DA-CH recommendations) recently increased their recommendation for children and adults from $5 \mu \mathrm{g} / \mathrm{d}$ (200 IU/d) to $20 \mu \mathrm{g} / \mathrm{d}(800 \mathrm{IU} / \mathrm{d})$, whereas the European require amount of vitamin $\mathrm{D}$ for adults remains at a daily intake is $5 \mathrm{mg} / \mathrm{d}(200 \mathrm{IU} / \mathrm{d})$, but the upper limit from $50 \mathrm{mg} / \mathrm{d}(2000 \mathrm{IU} / \mathrm{d})$ was increased to $100 \mathrm{mg} / \mathrm{d}$ (4000 IU/d) [27].

There are some limitations to the current study should be addressed for the future work. Firstly, since the dietary assessment was estimated. Therefore, the risk of over and under estimate was possible to occur. Secondly, we have used windiet for the analysis of the dietary intake and of course, this software has been developed for western diet, therefore it was very difficult for the researchers, to estimate the local food, we calculate all the recipes alone and inter it into the software. Finally, some participants forgot to take portions size pictures with them outside the home; therefore, they estimate their dietary intake. However, to our knowledge this is the first study, which implemented to find out the dietary intake of vitamin $\mathrm{D}$, we recommend to perform a national survey of not just for vitamin $\mathrm{D}$ but for the all other micronutrients since we don't have this guideline.

\section{CONCLUSION}

In conclusion, the reach dietary sources of vitamin $\mathrm{D}$ are not enough to provide the body adequate amount of vitamin D. In addition, obese and overweight individuals tend to have a less serum vitamin D status compared to the normal weight individuals and finally, recommended daily amount of vitamin D intake should be established for Kurdistan people.

\section{REFERENCE}

[1] Z. Naeem, "Vitamin d deficiency- an ignored epidemic," (in eng), no. 1658-3639 (Print).

[2] H. Al-Horani et al., "Nationality, Gender, Age, and Body Mass Index Influences on Vitamin D Concentration among Elderly Patients and Young Iraqi and Jordanian in Jordan," Biochemistry Research International, vol. 2016.

[3] C. Aranow, "Vitamin D and the immune system," (in eng), no. 1708-8267 (Electronic).

[4] K. L. How, J. A. Hazewinkel Ha Fau - Mol, and J. A. Mol, "Dietary vitamin D dependence of cat and dog due to inadequate cutaneous synthesis of vitamin D," (in eng), no. 0016-6480 (Print).

[5] M. Sahay and R. Sahay, "Rickets-vitamin D deficiency and dependency," (in eng), no. 2230-9500 (Electronic).

[6] M. F. Holick et al., "Prevalence of Vitamin D inadequacy among postmenopausal North American women receiving osteoporosis therapy," (in eng), no. 0021-972X (Print).

[7] K. D. Cashman, E. G. van den Heuvel, R. J. Schoemaker, D. P. Preveraud, H. M. Macdonald, and J. Arcot, "25Hydroxyvitamin D as a Biomarker of Vitamin D Status and Its Modeling to Inform Strategies for Prevention of Vitamin D Deficiency within the Population," (in eng), no. 2156-5376 (Electronic).

[8] J. E. Zerwekh, "Blood biomarkers of vitamin D status," (in eng), no. 1938-3207 (Electronic).

[9] P. Lips, "Vitamin D physiology," (in eng), no. 0079-6107 (Print).

[10] D. Heldenberg, Y. Tenenbaum G Fau - Weisman, and Y. Weisman, "Effect of iron on serum 25-hydroxyvitamin D and 
24,25-dihydroxyvitamin D concentrations," (in eng), no. 00029165 (Print).

[11] M. S. Calvo, C. N. Whiting Sj Fau - Barton, and C. N. Barton, "Vitamin D intake: a global perspective of current status," (in eng), no. 0022-3166 (Print)

[12] M. F. Holick et al., "Evaluation, treatment, and prevention of vitamin D deficiency: an Endocrine Society clinical practice guideline," (in eng), no. 1945-7197 (Electronic).

[13] W. Azhar, E. M. U. S. o. Health, and Sciences, A Determination of Vitamin D Status and Intake of Pregnant and Non-pregnant Saudi Arabian Women in Mecca, Saudi Arabia. 2009.

[14] M. Sadat-Ali, A. Al Elq, M. Al-Farhan, and N. A. Sadat, "Fortification with vitamin D: Comparative study in the Saudi Arabian and US markets," Journal of Family \& Community Medicine, vol. 20, no. 1, pp. 49-52, Jan-Apr 2013.

[15] T. Cranney A Fau - Horsley et al., "Effectiveness and safety of vitamin D in relation to bone health," (in eng), no. 1530-4396 (Print).

[16] A. O. Alsuwadia et al., "Prevalence of vitamin D deficiency in Saudi adults," Saudi Med J, vol. 34, no. 8, pp. 814-8, Aug 2013.

[17] B. Racinais S Fau - Hamilton, C. K. Hamilton B Fau - Li, J. Li Ck Fau - Grantham, and J. Grantham, "Vitamin D and physical fitness in Qatari girls," (in eng), no. 1468-2044 (Electronic).

[18] M. Tuffaha et al., "Deficiencies Under Plenty of Sun: Vitamin D Status among Adults in the Kingdom of Saudi Arabia, 2013," (in eng), no. 2250-1541 (Print).

[19] R. M. Kanan, Y. M. Al Saleh, H. M. Fakhoury, M. Adham, S. Aljaser, and W. Tamimi, "Year-round vitamin D deficiency among Saudi female out-patients," Public Health Nutr, vol. 16, no. 3, pp. 544-8, Mar 2013.

[20] M. F. Holick, "High prevalence of vitamin D inadequacy and implications for health," Mayo Clin Proc, vol. 81, no. 3, pp. 353-73, Mar 2006.

[21] A.-S. Ala Qatatsheh Reema. Tayyem Islam, Murad A. AlHoly, Abdallah S. Al-rethaia ""Vitamin D deficiency among Jordanian university students and employees," Nutrition \& Food Science, Vol. 45 Iss 1 pp. 68 - 82, vol. 45, pp. 68-82, 2015.

[22] H. L. Makin, D. A. Seamark, and D. J. Trafford, "Vitamin D and its metabolites in human breast milk," Archives of Disease in Childhood, vol. 58, no. 9, pp. 750-753, 1983.

[23] A. M. I. S. A. Ibraheem, "Alterations of Vitamin "D" level in Sera of Iraqi Population," Jornal of Kerbala University, vol. 5, no. 5, pp. 58-64, 2007.

[24] M. F. Holick, "Vitamin D deficiency," N Engl J Med, vol. 357, no. 3, pp. 266-81, Jul 192007.

[25] N. E. Cooke and J. G. Haddad, "Vitamin D binding protein (Gc-globulin)," (in eng), no. 0163-769X (Print).

[26] M. S. Calvo and S. J. Whiting, "Public health strategies to overcome barriers to optimal vitamin D status in populations with special needs," (in eng), no. 0022-3166 (Print).

[27] A. Schmid and B. Walther, "Natural Vitamin D Content in Animal Products," Advances in Nutrition, vol. 4, no. 4, pp. 453-462, 07/08 2013.

[28] A. H. Al-Elq, H. A. Sadat-Ali M Fau - Al-Turki, F. A. AlTurki Ha Fau - Al-Mulhim, A. K. Al-Mulhim Fa Fau - Al-Ali, and A. K. Al-Ali, "Is there a relationship between body mass index and serum vitamin D levels?," (in eng), no. 0379-5284 (Print).

[29] N. A. Al-Faris, "High Prevalence of Vitamin D Deficiency among Pregnant Saudi Women," Nutrients, vol. 8, no. 2, p. 77,

[30] H. Shi, W. H. Norman Aw Fau - Okamura, A. Okamura Wh Fau - Sen, M. B. Sen A Fau - Zemel, and M. B. Zemel, "1alpha,25-Dihydroxyvitamin D3 modulates human adipocyte metabolism via nongenomic action," (in eng), no. 1530-6860 (Electronic). 